\title{
The Impacts of Organizational Socialization Strategy and Proactive Behaviors on the Adaption of Newcomers*
}

\author{
Tianyan Xian \\ Beijing Institute of Technology, Zhuhai \\ Zhuhai, China 519088 \\ Gangxin Zheng \\ Beijing Institute of Technology, Zhuhai \\ Zhuhai, China 519088 \\ Bi Chen \\ Beijing Institute of Technology, Zhuhai \\ Zhuhai, China 519088
}

\author{
Linsheng Xiao** \\ Beijing Institute of Technology, Zhuhai \\ Zhuhai, China 519088 \\ **Corresponding Author \\ Jiacheng Lin \\ Beijing Institute of Technology, Zhuhai \\ Zhuhai, China 519088 \\ Dingji Chen \\ Beijing Institute of Technology, Zhuhai \\ Zhuhai, China 519088
}

\begin{abstract}
The study aims to explore the impacts of organizational socialization strategy and proactive behaviors on the adaption to the workplace of knowledge-based employees. Taking college graduates as research objects, we have made some conclusions based on the statistical analysis of 428 effective samples: (1) organizational socialization strategy has a positive effect on newcomers' adaption to the workplace and its dimensions (including the interpretation of tasks, the analysis of roles, international relationships and cultural adaption); (2) newcomers' proactive behaviors have a positive effect on their adaption to the workplace and its dimensions; (3) compared with the organizational socialization strategy, newcomers' proactive behaviors have a greater effect on the adaption to the workplace.
\end{abstract}

Keywords-organizational socialization strategy; the adaption to the workplace; newcomer's proactive behaviors; post-90s; knowledge-based employees

\section{INTRODUCTION}

Every year, there is a large number of university students graduating from school and starting to work in society. The transition from being a student to being a new worker is one of the most important socialization processes in a person's life. As the post-90s knowledge-based workers, the newly graduated college students have distinct personalities, diverse and novel thinking and more self-centered behaviors. The study found that after coming to a new workplace, the post-90s knowledgebased workers generally "had some difficulties in adapting to the new environment" [1]. Compared with the campus environment, there are more complex interpersonal

*This article is a phased outcome of the 2018 Guangdong University Student Science and Technology Innovation Cultivation Special Fund ("Climbing Plan") project (project number: pdjhb0619). relationships in the working environment [2], and the new graduates will have to face heavy working pressures [3]. The psychological impact brought by the difference between ideal and reality leads to the difficulty in changing the role of being a qualified worker, and the quality of adaptation is closely related to the individual's career development and career success.

Usually, the organization will adopt some strategies and methods to promote the socialization process of new employees, so that they can successfully complete the role change expected by the organization. But practice shows that it is impossible for new employees to complete the role change only by taking part in certain specific organizational activities or training. Faced with the anxiety brought about by the entering to a new organization [4], new employees need to actively make socialized behaviors to adapt to the new environment and become familiar with the new work [5], thereby reducing anxiety and improving self-happiness [6]

At present, the researches on organizational socialization of employees are mostly conducted by foreign people, which are based on the Western cultures. China's national conditions, cultural psychology and employee characteristics are very different from those of the Western countries. In addition, among the past studies which are focused on the impact of organizational socialization strategies and individual active socialized behaviors on the college graduates' adaption to the new workplace, there are few having compared the influence of the two socialization methods on the adaptability of new employees.

This paper takes the post-90s university graduates as the research objects, and discusses and compares the influence of 
organizational socialization strategies and new employees' proactive socialized behaviors on the adaption to the workplace of college graduates in the past research results, which will help reveal the occurrence and mechanism of organizational socialization of the university graduates and find the problems existing in the transition of university graduates from the role of "students" to "workers".

\section{RELATED CONCEPTS AND RESEARCH HYPOTHESES}

\section{A. Related Concepts}

1) Organizational socialization strategies: Schein is an early representative of organizational socialization research. Schein (1968) defined organizational socialization as the process by which new members learn and adapt to the value system of the organization and regulate their patterns of behavior according to the organization's needs. Through this process, the organization teaches the new members its values and behavioral norms [7]. Van Mannen and Schein (1979) divided organizational socialization strategies into six types of strategies: collective and individual strategies, formal and informal strategies, fixed and changing strategies, continuous and stochastic strategies, accompanying and separating strategies, and giving and depriving strategies. Jones (1986) attributed the above six strategies to three factors: situational factors, content factors, and social factors [8].

2) Proactive socialization behaviors: Louis (1980) first proposed the concept of Proactive Socialization Behaviors. He explained that the proactive socialization behaviors were made by the new employees to actively understand the situation in order to improve their adaptation to the organization and work during their transition of roles[9]. Ashford and Black (1996) proposed that there were seven types of proactive socialization behaviors of new employees, including information search, seeking feedback, daily social interaction, interpersonal network establishment, getting on well with superiors, negotiating work changes, and positive conception[10]. Crant (2000) concluded that there were two levels of proactive socialization behaviors of employees in the organization: one is the general behavior, mainly referring to behaviors of individuals to discover opportunities, challenge existing states, and create appropriate conditions; the second is the context-related active behavior, mainly referring to the proactive behaviors made by individuals in the process of socialization, feedback information collection, rationalization proposal, innovation, career management and stress management [11].

3) Work adaptability: Work adaptability is a concept that involves many fields and contains two-way interaction. Dawis and Lofquist (1984) believed that work adaptation was a process in which individuals and the environment interacted with each other and met the needs of each other. Individuals need to learn new skills and make appropriate behaviors to meet the requirements of the work environment and the position, and the work environment must also give individuals appropriate occupational fortifiers to meet their needs and values [12]. Hershenson (1978) elaborated on the work adaptation from the systemic and developmental perspective, that is, the content of work adaptation includes working role behavior, task performance, and degree of satisfaction of the worker [13]. There are many aspects about the work adaptation. Morrison (1993) believed that work adaptation included four aspects: mastery of work, role clarification, cultural adjustment, and social integration [14]. Tan Yali defines work adaptability as the process by which employees take the initiative to adapt to the organization, work tasks and work environment [15]. Based on the views of Morrison (1993) and Tan Yali, we tend to divide work adaptability into four dimensions in this study: task mastery, role clarification, interpersonal relationship and cultural adaptation. Among them, task mastery refers to new employees learning and mastering new work tasks and job performance; role clarification means that new employees get to know their own roles in work that are expected by other people; interpersonal relationship refers to new employees developing interpersonal relationships with their colleagues in the work environment; and cultural adaptation refers to new employees accepting the company's philosophy and values and integrating into the work environment.

\section{B. Research Hypotheses}

1) The impacts of organizational socialization strategies on the adaptation to work of new employees: Baker and Feldman (1991) pointed out that effective organizational socialization had a positive effect on both the organization and individuals [16]. Chao et al. (1994) found that organizational socialization has a significant positive impact on employees' performance in career (including their performance, attitude, organizational identity, and organizational adaptation). Klein and Weaver (2000) conducted field trials for 116 new employees in different occupations and found that employees who have participated in the organizational training had a higher emotional commitment to the organization than those who have not participated in the organizational training [15]. Jamie A. Gruman et al. (2005) found through empirical research that if the organization adopts an institutionalized organizational socialization strategy, the new employees will be more possible to make proactive socialization behaviors [17].

From the previous studies, it can be drawn that effective organizational socialization has a direct positive effect on the outcome variables at the individual, group and organizational levels. Based on the above points of view, in this study we assume that:

H1: Organizational socialization strategy has a positive impact on the adaptability of new employees.

H1(a): Organizational socialization strategy has a positive impact on the task mastery of new employees.

H1(b): Organizational socialization strategy has a positive impact on the role clarification of new employees. 
H1(c): Organizational socialization strategy has a positive impact on the interpersonal relationships of new employees.

H1(d): Organizational socialization strategy has a positive impact on the cultural adaptation of new employees.

2) The impacts of proactive socialization behaviors on the adaptation to work of new employees: To study the proactive socialization behaviors is to study how individuals can adapt to the working environment and positions as quickly as possible from the perspective of employees. The researchers pointed out that employees are not completely passive in the process of organizational socialization. In order to be familiar with the environment and eliminate the anxiety, employees will take the initiative to get information and feedback and establish their own interpersonal relationships, which is called the proactive socialization behaviors of new employees [14] [18] [9]. The research on the proactive socialization behaviors of new employees has been mainly focused on the behaviors of information and feedback search, and later the general socialization behaviors, network connections, communication of work changes, and observation and imitation have been gradually added to the contents of the researches. Miller and Jablin (1991) proposed that the behavior of searching for information helps to reduce individuals' role ambiguity and role conflicts [10]. Ostroff and Koziowski (1992) found that the higher the frequency of new employees looking for information, the higher degree of their satisfaction about work, work adaptability and organizational commitment, and the lower their working pressure and turnover intention[19]. Scholars believe that the proactive behaviors have a positive impact on the near-end results of new employees' adaptation to work, such as their role clarification, social integration and job competency, and also have a significant impact on far-end outcomes such as job satisfaction, organizational commitment and turnover intention. Accordingly, we have proposed the following hypotheses in this study:

H2: The proactive socialization behaviors of new employees have a positive impact on their work adaptability.

H2(a): The proactive socialization behaviors of new employees have a positive impact on the task mastery of new employees.

$\mathrm{H} 2$ (b): The proactive socialization behaviors of new employees have a positive impact on the role clarification of new employees.

$\mathrm{H} 2$ (c): The proactive socialization behaviors of new employees have a positive impact on the interpersonal relationship of new employees.

H2(d): The proactive socialization behaviors of new employees have a positive impact on the cultural adaptation of new employees.

3) The impacts of proactive socialization behaviors and organizational socialization strategies on the work adaptation of new employees: Peter Drucker (1966) suggested that knowledge-based workers referred to those who mastered and used symbols and concepts, and relied on their own knowledge or information to work. Compared with non knowledge-based employees, the knowledge-based workers have many special characteristics in personal traits, psychological needs, values and working methods. For example, they have a strong desire to achieve their self-worth, and have high creativity and autonomy. Liu Lihua (2006) also believed that knowledge-based workers had their own distinct characteristics: strong desire to achieve self-worth, distinctive personalities, mixed types of demands, outstanding ability to innovate, and strong desire to update their knowledge [20].

Due to the above characteristics of knowledge-based new employees, the influence of their own proactive socialization behaviors on their work is significantly stronger than that of their passive socialization through organizational strategies [21]. He Hui and Yang Jing (2016) found that compared with organizational socialization strategies, employees' proactive socialization behaviors had a greater impact on their work adaptation [22]. Zhu Yuanyuan (2016) believed that the organizational socialization strategy and proactive socialization behavior both had a significant positive impact on the socialization of behaviors of new employees, and the impact of personal initiative socialization is greater than that of organizational socialization behaviors [23]. Accordingly, we have proposed in this study that:

H3: Between the impacts of organizational socialization strategies and new employees' proactive socialization behaviors on their work adaptability, the proactive socialization behaviors of new employees have a greater impact on the work adaptability.

\section{RESEARCH METHODS}

\section{A. Research Objects}

We have chosen the newly graduated college students (with no more than 2 years of working experience) as the research objects in our study. We have given out questionnaires to collect data. In order to more rigorously verify the causal relationship between variables, we have given out the questionnaires at two different stages with a time interval of 4 months. The research variables in questionnaires given out at the first stage include the proactive socialization behaviors of new employees and organizational socialization strategies. A total of 500 questionnaires were distributed at this stage, and 486 were collected. The second stage is based on the first stage. There are variables such as work adaptability, career development and turnover intention of new employees in the questionnaires distributed at the second stage. A total of 480 questionnaires were distributed at this stage, and 450 questionnaires were collected. Among them, there were 22 invalid questionnaires having been removed, and 428 valid questionnaires were finally obtained. In order to ensure the authenticity of the data and improve the efficiency of doing the research, every research object was numbered before being surveyed, and the team members are responsible for tracking the samples to ensure that the sample data from the two stages of research are consistent. 


\section{B. Research Tools}

1) Organizational socialization strategy: This variable was measured through Jones's Organizational Socialization Strategy Questionnaire [8], in which the organizational socialization strategy has been divided into three dimensions: situational factors, content factors, and social factors. In the questionnaire, the situational factors were measured through 4 items, social factors 4 items, and content factors 5 items. So there was a total of 13 items in the questionnaire. In this study, the internal consistency coefficient of the overall scale was 0.861 . The internal consistency coefficients of situational factors, social factors and content factors are respectively $0.847,0.850$, and 0.852 . In this study, the organizational socialization strategy was measured integrally.

2) Individual proactive socialization behaviors: We have used Ashford's simplified scale as the questionnaire, selected the five dimensions of information search, feedback search, positive conception, participation in work-related activities, and relationship establishment as the content of proactive socialization behaviors, and there was a total of 18 items in the questionnaire. The Likert 5-point scoring method has been used in the scale, in which points from 1 to 5 represent attitudes of "completely disagree" to "completely agree". In this study, the internal consistency coefficient of the overall scale was 0.895 .

3) Work adaptability of university graduates: The questionnaire prepared by Morrison (1993) and Ashford (1986) has been adopted. The work adaptability has been divided into four dimensions in this questionnaire: task mastery, role clarification, interpersonal relationship and cultural adaptation, and there was a total of 16 questions in the questionnaire. In this study, the internal consistency coefficient of the overall scale is 0.905 , and the internal consistency coefficients of the four dimensions are 0.819 , $0.790,0.806$ and 0.798 , respectively.

4) Controlled variables: Several common demographic variables were selected as the controlled variables, including the gender, education level, and years of working.

5) Data analysis: SPSS19.0 was used to conduct data analysis, including correlation analysis, hierarchical regression analysis, etc.

\section{DATA ANALYSIS AND RESULTS}

\section{A. Descriptive Statistical Analysis}

The mean, standard deviation and correlation coefficients of each variable are shown in "Table I". The data shows that organizational socialization strategies are significantly positively correlated with the work adaptability $(r=.213$, $\mathrm{p}<0.01$ ), and are significantly positively correlated with the dimensions of work adaptability including task mastery, role clarification, interpersonal relationship and cultural adaptation $(\mathrm{r}=.117, \mathrm{p}<0.05 ; \mathrm{r}=.110, \mathrm{p}<0.05 ; \mathrm{r}=.158, \mathrm{p}<0.01 ; \mathrm{r}$ $=.285, \mathrm{p}<0.01)$. There is a significant positive correlation between the proactive socialization behaviors of new employees and the work adaptability $(\mathrm{r}=.272, \mathrm{p}<0.01)$, and there is a significant positive correlation between the proactive socialization behaviors and the task mastery, role clarification, interpersonal relationship and cultural adaptation of work adaptability $(\mathrm{r}=.160, \mathrm{p}<0.01 ; \mathrm{r}=.165, \mathrm{p}<0.01 ; \mathrm{r}=.267, \mathrm{p}<$ $0.01 ; \mathrm{r}=.281, \mathrm{p}<0.01)$.

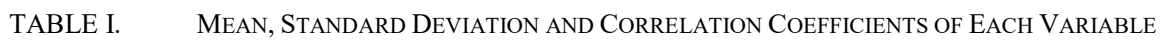

\begin{tabular}{|c|c|c|c|c|c|c|c|c|c|c|c|}
\hline & $\mathbf{M}$ & SD & 1 & 2 & 3 & 4 & 5 & 6 & 7 & 8 & 9 \\
\hline Gender & .54 & .50 & & & & & & & & & \\
\hline Education level & 1.91 & .35 & -.039 & & & & & & & & \\
\hline Working time & 2.81 & 1.06 & .022 & -.070 & & & & & & & \\
\hline $\begin{array}{l}\text { Organizational } \\
\text { socialization }\end{array}$ & 3.83 & .48 & .006 & -.021 & -.022 & & & & & & \\
\hline Task mastery & 3.88 & .58 & .005 & -.003 & $.158 * *$ & $.117 *$ & & & & & \\
\hline Role clarification & 3.89 & .56 & .041 & .028 & $.155^{* *}$ & $.110^{*}$ & $.735^{* *}$ & & & & \\
\hline $\begin{array}{l}\text { Interpersonal } \\
\text { relationship }\end{array}$ & 3.89 & .58 & .033 & .014 & $.202 * *$ & $.158^{* *}$ & $.557 * *$ & $.603 * *$ & & & \\
\hline Cultural adaptation & 3.60 & .70 & -.043 & .001 & $.112 *$ & $.285^{* *}$ & $.420 * *$ & $.465 * *$ & $.553^{* *}$ & & \\
\hline $\begin{array}{l}\text { Proactive } \\
\text { socialization of new } \\
\text { employees }\end{array}$ & 3.99 & .44 & -.058 & -.047 & .001 & $.629 * *$ & $.160 * *$ & $.165^{* *}$ & $.267 * *$ & $.281 * *$ & \\
\hline Adaptability to work & 3.82 & .49 & .007 & .011 & $.190^{* *}$ & $.213^{* *}$ & $.818^{* *}$ & $.844 * *$ & $.826^{* *}$ & $.774 * *$ & $.272^{* *}$ \\
\hline
\end{tabular}

${ }^{\mathrm{a} .}$ Remarks: $1 .{ }^{* *} \mathrm{p}<0.01,{ }^{*} \mathrm{p}<0.05 ; 2$. Gender $(0=$ male, $1=$ female); education level ( $1=$ college, $2=$ undergraduate, $3=$ postgraduate); working time $(1=$ not more than 3 months, $2=3-6$ months, $3=6-12$ months, $4=12$ months 


\section{B. Hypothesis Testing}

As shown in "Table II", in the study of H1, Model 2 ( $\beta$ $=.218, \mathrm{p}<0.001)$ indicates that the organizational socialization strategy has a significant positive impact on the work adaptability of new employees, and the adjusted overall model explanatory power is $7.6 \%$, and the $F$ value is 9.727 , so the higher the degree of organizational socialization, the stronger the new employees' work adaptability; the models 4, 6, 8 and 10 are the regression data of the organizational socialization strategy for the various dimensions of work adaptability, showing that the task mastery $(\beta=.121, \mathrm{p}<0.05)$, role clarification $(\beta=114, \mathrm{p}<0.05)$, interpersonal relationship $(\beta$ $=.163, \mathrm{p}<0.001)$ and cultural adaptation $(\beta=.288, \mathrm{p}<0.001)$ were all positively impacted by the organizational socialization strategy, and the adjusted overall model explanatory powers are $3 \%, 3.1 \%, 6 \%$ and $8.9 \%$, respectively, and the $\mathrm{F}$ values are $4.341,4.407,7.812$ and 11.445 , respectively, indicating that the higher degree of organizational socialization, the higher degree of task mastery, role clarification, interpersonal relationship and cultural adaptation. So it can be concluded that $\mathrm{H} 1$ is true.

TABLE II. REGRESSION ANALYSIS OF ORGANIZATIONAL SOCIALIZATION ON WORK ADAPTABILITY AND ITS MULTIDIMENSIONAL VARIABLES

\begin{tabular}{|c|c|c|c|c|c|c|c|c|c|c|}
\hline & \multicolumn{2}{|c|}{ Work Adaptability } & \multicolumn{2}{|c|}{ Task Mastery } & \multicolumn{2}{|c|}{ Role Clarification } & \multicolumn{2}{|c|}{$\begin{array}{c}\text { Interpersonal } \\
\text { Relationship }\end{array}$} & \multicolumn{2}{|c|}{ Cultural Adaptation } \\
\hline & M1 & $M 2$ & M3 & M4 & M5 & M6 & $M 7$ & M8 & M9 & M10 \\
\hline \multicolumn{11}{|l|}{$\begin{array}{l}\text { Controlled } \\
\text { variables }\end{array}$} \\
\hline Gender & .004 & .003 & .001 & .001 & .039 & .039 & .030 & .029 & -.046 & -.047 \\
\hline $\begin{array}{l}\text { Education } \\
\text { level }\end{array}$ & .025 & .030 & .008 & .010 & .041 & .043 & .030 & .033 & .007 & .013 \\
\hline Working time & $.191 * * *$ & $.196 * * *$ & $.158 * * *$ & $.161 * * *$ & $.157 * * *$ & $.159 * * *$ & $.203 * * *$ & $.207 * * *$ & $.113^{*}$ & $.120 * *$ \\
\hline \multicolumn{11}{|l|}{$\begin{array}{l}\text { Independent } \\
\text { variable }\end{array}$} \\
\hline R2 & .037 & .084 & .025 & .039 & .027 & .040 & .042 & .069 & .015 & .098 \\
\hline Adjust R2 & .030 & .076 & .018 & .030 & .020 & .031 & .036 & .060 & .008 & .089 \\
\hline F-value & 5.366 & 9.727 & 3.609 & 4.341 & 3.923 & 4.407 & 6.243 & 7.812 & 2.105 & 11.445 \\
\hline P-value & .001 & .000 & .013 & .002 & .009 & .002 & .000 & .002 & .099 & .000 \\
\hline
\end{tabular}

As shown in "Table III", in the test of H2, the model 12 ( $\beta$ $=.275, \mathrm{p}<0.001)$ indicates that the proactive socialization of new employees has a positive impact on their work adaptability, and the adjusted overall model explanatory power is $10.3 \%$. The $\mathrm{F}$ value is 13.323 , so the higher degree of proactive socialization of new employees, the stronger their work adaptability; The models 14, 16, 18 and 20 respectively show the impacts of new employees' proactive socialization on the fractal dimension variables of work adaptability such as task mastery $(\beta=.163, p<0.001)$, role clarification $(\beta=.170$, $\mathrm{p}<0.001)$, interpersonal relationship $(\beta=.163, \mathrm{p}<0.001)$ and cultural adaptation $(\beta=.280, p<0.001)$, and the impact of the proactive socialization on these variables is positive. The adjusted overall model explanatory powers are $4.2 \%, 4.7 \%$, $10.7 \%$ and $8.4 \%$ respectively, and the $\mathrm{F}$ values are 5.643 , $6.249,13.808$ and 10.795 , respectively. So, the higher the degree of new employees' proactive socialization is, the higher the degree of their task mastery, role clarification, interpersonal relationship and cultural adaptation will be. From the above, it can be drawn that $\mathrm{H} 2$ is true.

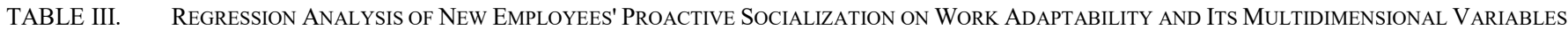

\begin{tabular}{|c|c|c|c|c|c|c|c|c|c|c|}
\hline & \multicolumn{2}{|c|}{ Work Adaptability } & \multicolumn{2}{|c|}{ Task Mastery } & \multicolumn{2}{|c|}{ Role Clarification } & \multicolumn{2}{|c|}{$\begin{array}{c}\text { Interpersonal } \\
\text { Relationship } \\
\end{array}$} & \multicolumn{2}{|c|}{ Cultural Adaptation } \\
\hline & M11 & $M 12$ & $M 13$ & $M 14$ & $M 15$ & M16 & M17 & M18 & M19 & $M 20$ \\
\hline \multicolumn{11}{|l|}{$\begin{array}{l}\text { Controlled } \\
\text { variables }\end{array}$} \\
\hline Gender & .004 & .021 & .001 & .011 & .039 & .049 & .030 & .046 & -.046 & -.029 \\
\hline $\begin{array}{l}\text { Education } \\
\text { level }\end{array}$ & .025 & .039 & .008 & .016 & .041 & .049 & .030 & .043 & .007 & .021 \\
\hline Working time & $.191 * * *$ & $.192 * * *$ & $.158 * * *$ & $.158 * * *$ & $.157 * * *$ & $.157 * * *$ & $.203 * * *$ & $.203 * * *$ & $.113 *$ & $.114^{*}$ \\
\hline
\end{tabular}




\begin{tabular}{|c|c|c|c|c|c|c|c|c|c|c|}
\hline & \multicolumn{2}{|c|}{ Work Adaptability } & \multicolumn{2}{|c|}{ Task Mastery } & \multicolumn{2}{|c|}{ Role Clarification } & \multicolumn{2}{|c|}{$\begin{array}{c}\text { Interpersonal } \\
\text { Relationship }\end{array}$} & \multicolumn{2}{|c|}{ Cultural Adaptation } \\
\hline & M11 & M12 & M13 & M14 & M15 & M16 & M17 & $M 18$ & M19 & M20 \\
\hline \multicolumn{11}{|l|}{$\begin{array}{l}\text { Independent } \\
\text { variable }\end{array}$} \\
\hline $\begin{array}{l}\text { Proactive } \\
\text { socialization }\end{array}$ & & $.275^{* * *}$ & & $.161 * * *$ & & $.170 * * *$ & & $.271 * * *$ & & $\begin{array}{l}.280 * * \\
*\end{array}$ \\
\hline $\mathrm{R} 2$ & .037 & .112 & .025 & .051 & .027 & .056 & .042 & .115 & .015 & .093 \\
\hline Adjust R2 & .030 & .103 & .018 & .042 & .020 & .047 & .036 & .107 & .008 & .084 \\
\hline$\Delta \mathrm{R} 2$ & .037 & .075 & .025 & .026 & .027 & .029 & .042 & .073 & .015 & .078 \\
\hline F-value & 5.366 & 13.323 & 3.609 & 5.643 & 3.923 & 6.249 & 6.243 & 13.808 & 2.105 & 10.795 \\
\hline P-value & .001 & .000 & .013 & .000 & .009 & .000 & .000 & .000 & .099 & .000 \\
\hline
\end{tabular}

In the test of $\mathrm{H} 3$, it is found that the impact of organizational socialization on the work adaptability, task mastery, role clarification and interpersonal relationship is not significantly positive, and the organizational socialization only has a positive impact on cultural adaptation $(\beta=186, \mathrm{p}<0.01)$. However, the proactive socialization has a positive impact on work adaptability $(\beta=.228, p<0.001)$, task mastery $(\beta=.141$, $\mathrm{p}<0.05)$, role clarification $(\beta=.163, \mathrm{p}<0.01)$, interpersonal relationship $(\beta=.279, \mathrm{p}<0.001)$ and cultural adaptation $(\beta$ $=.162, \mathrm{p}<0.01)$. So it can be concluded that $\mathrm{H} 3$ is true. The results of the variable comparison are shown in "Table IV":

TABLE IV. COMPARATIVE ANALYSIS OF THE INFLUENCE OF ORGANIZATIONAL SOCIALIZATION STRATEGY AND NEW EMPLOYEES' PROACTIVE SOCIALIZATION ON VARIOUS DIMENSIONS OF WORK ADAPTABILITY

\begin{tabular}{|c|c|c|c|c|c|c|c|c|c|c|}
\hline & \multicolumn{2}{|c|}{ Work Adaptability } & \multicolumn{2}{|c|}{ Task Mastery } & \multicolumn{2}{|c|}{ Role Clarification } & \multicolumn{2}{|c|}{$\begin{array}{l}\text { Interpersonal } \\
\text { Relationship }\end{array}$} & \multicolumn{2}{|c|}{ Cultural Adaptation } \\
\hline & $M 21$ & $M 22$ & $M 23$ & $M 24$ & $M 25$ & $M 26$ & $M 27$ & $M 28$ & $M 29$ & м30 \\
\hline \multicolumn{11}{|l|}{$\begin{array}{l}\text { Controlled } \\
\text { variables }\end{array}$} \\
\hline Gender & .004 & .017 & .001 & .010 & .039 & .049 & .030 & .046 & -.046 & -.037 \\
\hline Education level & .025 & .038 & .008 & .015 & .041 & .049 & .030 & .043 & .007 & .019 \\
\hline Working time & $.191 * * *$ & $.193 * * *$ & $.158 * * *$ & $.159 * * *$ & $.157 * * *$ & $.157 * * *$ & $.203 * * *$ & $.203 * * *$ & $.113 *$ & $.118 *$ \\
\hline \multicolumn{11}{|l|}{$\begin{array}{l}\text { Independent } \\
\text { variables }\end{array}$} \\
\hline $\begin{array}{l}\text { Proactive } \\
\text { socialization }\end{array}$ & & $.228 * * *$ & & $.141^{*}$ & & $.163 * *$ & & $.279 * * *$ & & $.162 * *$ \\
\hline $\begin{array}{l}\text { Organizational } \\
\text { socialization }\end{array}$ & & .075 & & .032 & & .012 & & -.013 & & $.186 * *$ \\
\hline $\mathrm{R} 2$ & .037 & .115 & .025 & .051 & .027 & .056 & .042 & .116 & .015 & .113 \\
\hline Adjust R2 & .030 & .105 & .018 & .040 & .020 & .045 & .036 & .105 & .008 & .103 \\
\hline$\Delta \mathrm{R} 2$ & .037 & .079 & .025 & .026 & .027 & .029 & .042 & .073 & .015 & .099 \\
\hline F-value & 5.366 & 11.000 & 3.609 & 4.562 & 3.923 & 4.995 & 6.243 & 11.031 & 2.105 & 10.804 \\
\hline P-value & .001 & .000 & .013 & .000 & .009 & .000 & .000 & .000 & .099 & .000 \\
\hline
\end{tabular}

\section{CONCLUSION}

\section{A. Conclusion and Discussion}

1) Relationship between organizational socialization strategies and new employees' work adaptability: The research shows that there is a significant positive correlation between organizational socialization strategy and work adaptability, and there is a significant positive correlation between organizational socialization strategy and fractal dimensions of work adaptability. The hypotheses of $\mathrm{H} 1$, H1(a), H1(b), H1( c) and H1(d) are all true. The analysis results show that organizational socialization strategies have very important impacts on both new employees and the organization. Not only does the organization enable employees to integrate into the organizational culture and environment as quickly as possible through specific strategies, but these strategies have a lasting impact on the behaviors and attitudes of employees, enabling them to gradually master and skillfully use knowledge and skills to complete work tasks in the organization, gradually explore, find out, and clarify their own roles, and establish their own network of relationships.

2) The relationship between proactive socialization behaviors and the adaptation to work of new employees: The research shows that there is a significant positive correlation between the proactive socialization of new employees and their work adaptability, and there is a significant positive correlation between the proactive socialization and the fractal 
dimensions of work adaptability, proving that the hypotheses of H2, H2(a), H2(b), H2 (c) and H2(d) are all true. The post $90 \mathrm{~s}$ are proficient in using the social media. They can reduce their ineffective performance in the workplace and better adapt to the work by making proactive socialization behaviors such as making full use of social resources, actively participating in work-related activities, actively searching for information and seeking feedback from leaders and colleagues, establishing relationships with superiors and colleagues, and developing their own networks of interpersonal relationships.

3) Relationship between organizational socialization strategy, proactive socialization behavior and new employees' adaptation to work: Research shows that between the organizational socialization and new employees' proactive socialization, the proactive socialization of new employees has a greater positive impact on their work adaptability, proving that the hypothesis of $\mathrm{H} 3$ is true.

The post-90s university graduates are newly-employed knowledge-based workers. In the early stage of socialization, they often learn and master relevant skills and work norms through observation and learning, and they often have their own thoughts on how to solve practical work problems. And as they have just started to work, they are generally energetic and have enough energy to cope with the difficulties possibly encountered in work and conduct positive self-adjustment. Moreover, during the period of new employees' adaptation to work, the interaction of new and old employees is also conducive to the passing of the organization's role expectations and policies to the new employees.

The organizational socialization strategies only make effects within a certain period of time. And with the changes of the internal and external environment of the organization, it is impossible for the organization to maintain optimal management performance at all times, and it is impossible for the organization to pay attention to the situation of each new employee. Highly proactive employees will take the initiative to conduct observation and inquiry, participate in work-related activities, and establish relationships, gaining sufficient information and useful resources to make themselves adapt to the new work environment and meet the new work requirements more quickly. Therefore, the proactive socialization behavior has a greater contribution to the work adaptability of new employees.

However, it is worth noting that organizational socialization strategies play a more important role in promoting the cultural adaptation of new employees than individual proactive socialization. This shows that the organization is still an irreplaceable role in promoting new members to learn and adapt to the values and norms of the organization.

\section{B. Practical Enlightenment}

First, organizations should provide employees with comprehensive pre-job training and career planning. Formal pre-job training can not only enable new employees to further understand the culture and philosophy of the company, but also enable employees to form a team spirit. And pre-job training can help new employees get the information they need to adapt to their work faster and better. In addition, organizations can also help employees develop their career plans that satisfy the needs of both organizational development and individual development, so that employees can have more clear goals in their future development during their working time in the organization, which will help improve the work adaptability of new employees.

Second, new employees should establish good interpersonal relationships and actively seek information and feedback in the organization. The more people a new employee has established good relationships with in the organization, the more opportunities he will have. New employees should establish good relationships with colleagues and managers on various occasions. New employees should make full use of resources they have access to to improve their work adaptability. At the same time, new employees need to maintain a good and positive attitude when entering into the workplace, which will also help them adapt to the work environment more quickly.

\section{Limitations of the Research}

We have invested a lot of energy and time in this research and to study and analyze the proposed hypotheses. However, there are still some shortcomings in this research. Firstly, although the deviations caused by objective factors have been reduced as much as possible in the process of designing the questionnaire, since the questionnaires were filled in by different individuals, they have inevitably filled in the questionnaires with their own subjective consciousness and emotions, which will more or less lead to deviations in the final data. Secondly, the subjects of this research are mainly the newly-graduated and newly-employed university students in Guangdong Province, which is not representative enough.

\section{REFERENCES}

[1] He Hui, Huang Yue. The Impact of Organizational Socialization Strategy on the Proactive Socialization Behavior and Work Adaptability of New Employees - Based on an Intermediary Adjustment Model[J]. Review of Economy and Management, 2016, 32(05): pp.37-44. (in Chinese)

[2] Xu Changjiang, Tao Xiaohong. Analysis on the Causes and Countermeasures of High Turnover Rate of Post-90s Knowledge-based Workers[J]. Enterprise Reform and Management, 2017, (6): pp.69-71. (in Chinese)

[3] Zhang Yue, Zhang Guangxu. Research on the relationship between job values and turnover intention of post-90s knowledge-based workers: the regulation of psychological endurance [J]. China Market, 2016, (22): pp.112-113. (in Chinese)

[4] Ashforth B E, Sluss D M and SaksA M.Socialization tactics, proactive behavior, and newcomer learning: Integrating socialization models.Journal of Vocational Behavior, 2007,70: pp.447-462.

[5] Li Yanping, Xu Jia. The new generation of employees: the impact of psychological and behavioral characteristics on organizational socialization [J]. Economic Management Journal, 2013, 35 (4), pp.6170. (in Chinese)

[6] AM Saks,JA Gruman,H Cooper-Thomas.The neglected role of proactive behavior and outcomes in newcomer socialization. Journal of Vocational Behavior, 2011,79 (1): pp.36-46.

[7] Edgar H.Schein.Organization and the Profession of Management [J].Industrial Management Review. 1968,9,(2): pp.1-16. 
[8] Liu Mi. Research on the Influence of Organizational Socialization Strategy on College Graduates' Work Adaptability [D]. Central China Normal University, 2007. (in Chinese)

[9] Xing Xiaoming. Research on the relationship between new employees' socialization, social capital and organizational commitment [D]. Nanchang: Jiangxi University of Finance and Economics, 2010. (in Chinese)

[10] Ashford, S. J. \& Black, J. S. Proactivity during organizational entry: The role of desire for control.Journal of Applied Psychology, 81, 1996, pp.199-214.

[11] Crant, J. M., \& Bateman, T. S. Charismatic leadership viewed from above: The impact of proactive personality. Journal of Organizational Behavior, 2000 (21), pp.63-75.

[12] Dawis, R.V. Lofquist, L.H.. Apsychological theory of work adjustment[M]. University of Minnesota Press, 1984.

[13] Hershenson, D.B., Lavery, G.J..Sequencing of vocational development Stages: Futher studies [J]. Journal of Voca-tional Behavior, 1978(12).

[14] Morrison , E.W..Longitudinal study of the effects of information seeking on new-comer socialization[J].Journal of Applied Psychology, 1993a, 78(2): pp.173-183. (in Chinese)

[15] Tan Yali. Research on the development model of new employees' adaptation to work[D]. Hubei: Huazhong University of Science and Technology, 2005.

[16] Baker III H, Feldman D C. Linking organizational socialization tactics with corporate human resource management strategies. Human Resource Management Review, 1991,1(3):pp.193- 202.

[17] Klein H J, Weaver N A. The effectiveness of an organizational level orientation training program in the socialization of new hires. Personnel Psychology, 2000,53: pp.47- 66.

[18] Griffin, A.E, Colell, a A, Goparaju S.Newcomer and organizational socialization tactics: an interactionist perspective[J]. Human Resource Managemment Review, 2000, 10(4):pp.453-474

[19] Ostroff, C.,\& Kozlowski, S.W. Organizational socialization as a learning process: the role of information acquisition. Personnel Psychology, 1992,45, pp.849-874.

[20] Liu Lihua. Research on performance management of knowledge-based workers in enterprises [D]. Shandong University, 2006. (in Chinese)

[21] Li Congrong, Zhang Shengtai. Research on the Influence of Information Seeking Behavior on Organizational Socialization — From the Perspective of Knowledge-based New Employees[J]. Science Research Management, 2011, 32(04): pp.106-112. (in Chinese)

[22] He Hui, Yang Jing. A comparative study of the influence of organizations and individuals on the socialization of new employees [J]. China Labour, 2016 (20): pp.77-83. (in Chinese)

[23] Lin Liping. Research on the relationship between initiative personality, organizational socialization strategy and proactive socialization behaviors of new employees [D]. Xiamen University, 2009. (in Chinese)

[24] He Hui, Huang Yue. Research on organizational socialization strategy and work adaptability of new employees[J]. Chinese Journal of Management,2015,12(10): pp.1457-1464. (in Chinese)

[25] Wang Lei. Research on the Relationship between New Employees' Work Expectation and Organizational Socialization[D]. Liaoning University, 2013. (in Chinese)

[26] Liu Fengying, Mou Lei. How to improve the work adaptability of new employees in enterprises [J]. Commercial Times, 2010 (11): pp.74-75. (in Chinese)

[27] Yang An, Li Yanping. A Review of the Research on Organizational Socialization Theory [J]. Economic Management Journal, 2007 (21): pp.91-96. (in Chinese)

[28] Wang Yanfei, Zhu Yu. Organizational Socialization: Concept, Structure and Influence Effect [J]. Science and Technology Management Research, 2010, 30 (02): pp.201-203. (in Chinese)

[29] Shi Feng. Research on the Organizational Socialization Strategy for Knowledge-based Workers [J].Market Modernization, 2007(36): p39. (in Chinese)

[30] Yang Shiming, Liu Yiying. The Construction of the Operational Model of the Organizational Socialization of the Post-90s New Employees -
From the Perspectives of Employees and Organizations [J].Leadership Science,2018(02):pp.51-53. (in Chinese)

[31] Yan Ming, Tu Hongwei, Li Ji. The Definition and Structural Dimensions of New Employees' Organizational Socialization from the Perspective of Identity Theory[J].Advances in Psychological Science,2011,19(5), pp.624-632. (in Chinese)

[32] Wan Juan. Research on organizational socialization strategy and its effects on fresh university graduates [D]. Capital University of Economics and Business, 2008. (in Chinese)

[33] Li Chan, Yao Chong. Optimization of the Management System for Post-90s College Students from the Perspective of Organizational Socialization Strategy[J]. Value Engineering, 2013, 32(22): pp.6-8.(in Chinese) 